IZA DP No. 4997

The Importance of Skill Measurement for Growth Accounting

Øivind A. Nilsen

Arvid Raknerud

Marina Rybalka

Terje Skjerpen

June 2010 


\title{
The Importance of Skill Measurement for Growth Accounting
}

\author{
Øivind A. Nilsen \\ Norwegian School of Economics and Business Administration \\ and IZA
}

Arvid Raknerud

Statistics Norway

Marina Rybalka

Statistics Norway

Terje Skjerpen

Statistics Norway

\author{
Discussion Paper No. 4997 \\ June 2010
}

IZA

P.O. Box 7240

53072 Bonn

Germany

Phone: +49-228-3894-0

Fax: +49-228-3894-180

E-mail: iza@iza.org

Any opinions expressed here are those of the author(s) and not those of IZA. Research published in this series may include views on policy, but the institute itself takes no institutional policy positions.

The Institute for the Study of Labor (IZA) in Bonn is a local and virtual international research center and a place of communication between science, politics and business. IZA is an independent nonprofit organization supported by Deutsche Post Foundation. The center is associated with the University of Bonn and offers a stimulating research environment through its international network, workshops and conferences, data service, project support, research visits and doctoral program. IZA engages in (i) original and internationally competitive research in all fields of labor economics, (ii) development of policy concepts, and (iii) dissemination of research results and concepts to the interested public.

IZA Discussion Papers often represent preliminary work and are circulated to encourage discussion. Citation of such a paper should account for its provisional character. A revised version may be available directly from the author. 
IZA Discussion Paper No. 4997

June 2010

\section{ABSTRACT}

\section{The Importance of Skill Measurement for Growth Accounting}

In a growth accounting context one usually constructs a quality adjusted index of labor services by aggregating over predefined groups of workers, using the groups' relative wage bills as weights. In this article we suggest a method based on decomposing individual predicted wages into a skill-related part and a part unrelated to skill, where the former consists of both observed and unobserved components. The predicted wages, associated with individual skill attributes, are sorted and classified into deciles. The median predicted skill-related wage in each decile is used to construct an alternative skill-adjusted index of labor services. We find that Total Factor Productivity (TFP) growth decreases significantly when using the latter method. This means that when using the alternative method one explains more of the growth in labor productivity than what a more traditional labor quality adjustment procedure does.

JEL Classification: $\quad$ C23, D24, J24, J31

Keywords: TFP growth, skill measures, wage equation

Corresponding author:

Terje Skjerpen

Statistics Norway

PO Box 8131 Dep

NO-0033 Oslo

Norway

E-mail: terje.skjerpen@ssb.no

\footnotetext{
*We appreciate many useful comments from two anonymous referees and an editor.
} 


\section{Introduction}

In the growth accounting literature it has since long been acknowledged that one should pay attention to improvements in labor quality (see for instance Jorgenson et al., 1987, and Bureau of Labor Statistics, 1993). Ignoring the labor quality component when carrying out growth accounting implies that improvements in labor quality are allocated to the residual TFP growth component, which incorporates the contribution of all unobserved production factors and hence is difficult to interpret. The issue of productivity measurement with heterogeneous labor is discussed in OECD (2001, chapter 4.5), Ahmad et al. (2003, chapter 4.5) and Boulhol and Turner (2009). These references also provide some recommendations with regard to practical implementation.

The idea behind skill-adjusting labor is based on the fact that labor is not a homogeneous input, but differs in skill and efficiency. If one replaces a worker with a more productive one, assuming that they work the same number of man-hours, an increase in output will, ceteris paribus, be the result. The question then is how to measure differences in productivity. An early idea put forward by Griliches (1960) was to look at relative wages. In a perfect labor market wage differences should mirror differences in productivity. The approach pursued in the present paper also builds on this idea, but is modified. We view variation in skill related predicted wages as more informative about variation in productivity than the raw hourly wages. Observed wage differences do not only reflect skill differences, but also variables unrelated to skill, such as regional and temporal variations in labor market conditions, rent sharing, unions' bargaining power, and transient wage fluctuations.

A common method used to construct an index of skill-adjusted labor input is to divide the workers into several groups and then let the growth in labor input services be a weighted sum of the increases in man-hours in each of the groups. As Zoghi (2008) points out one may calculate weights in different ways. The simplest way is to utilize the observed wage bills associated with the different groups. An alternative to using observed mean wages, which may be somewhat volatile, is to employ mean predicted wages from a wage equation. Bolli and Zurlinden (2009), Lacuesta et al. (2008) and Schwerdt and Turunen (2007) represent, in a broad sense, recent contributions within this type of approach. These contributions focus on robustness issues in different 
dimensions. For instance Bolli and Zurlinden (2009) are occupied with the implications of taking account of unobserved worker characteristics, while Lacuesta et al. (2008) have a special focus on selection problems caused by a substantial amount of inflow of immigrant workers to Spain.

The main contribution of the current paper is to suggest an alternative method for handling heterogeneity of labor within a growth accounting framework. We start out by estimating a wage equation at the industry level using a panel data model for eleven manufacturing industries. As explanatory variables in the equation we include variables related to individual skill or personal attributes; that is, length of education, experience, type of education and gender. In addition we include dummies for local labor market areas and fixed effects for years. From the estimated wage equation we extract what one may label the skill component of the predicted wage, which only captures the effects of observed and unobserved individual variables. These predicted wages are sorted in ascending order and divided in deciles. In each year we then know which decile the worker belongs to and how many man-hours he/she contributes with. This information is used to construct an index of skill-adjusted labor. The change in this index is a weighted average of the change in man-hours for each of the 10 groups. To calculate the weights we use median values of the skill-related predicted wages within each decile.

The estimated wage equations (one for each of the industries) are also utilized in conjunction with the benchmark method, where we divide the observations into 12 cells distinguishing between high and low education, three intervals of experience, and gender. For each year we calculate the total number of man-hours and the mean of the predicted (skill related) wages in each of the cells. This information is used to derive an index of labor services.

We consider calculation of TFP growth at the industry level when labor is treated in three different ways. In the first case labor is considered a homogeneous input variable. The second case corresponds to what we just referred to as the benchmark method, whereas in the third case we calculate TFP growth using the new method put forward in this article. We find that the TFP growth diminishes when one goes from the case with homogeneous labor to the benchmark method and even further 
when one goes from the benchmark method to the decile-based method proposed in this paper. For the manufacturing industry as a whole the annual mean TFP growth in the sample period is 2.5 percent when labor is treated as a homogeneous input, 2.3 percent when skill is accounted for by the benchmark method and 2.0 percent when using the decile-based method.

The paper proceeds as follows. In Section 2 we describe the data used in our analysis. Section 3 deals with classification of labor according to skill. In Section 4, we calculate growth in total factor productivity (TFP) applying the different ways of measuring labor input. Section 5 concludes the paper.

\section{Data}

For this study we use a rich employer-employee panel data set on Norwegian firms, covering the period 1995-2005. The sample is based on information from limited dependent companies (i.e., the smallest legal unit). We have constructed panels of annual firm-level data for Norwegian firms in eleven manufacturing industries, accounting for about 90 percent of total man-hours in manufacturing.

Five different sources of Norwegian micro data are used. Two of them are firmlevel data sets. One of the firm-level data sets is based on the accounts statistics of limited dependent companies, and the other comprises structural statistics for different industrial activities. These data sources provide information on value-added and capital at the end of the year in constant prices (for details about the capital variable see Raknerud et al., 2007). The three remaining data sets contain individual-level data. These are the Register of Employers and Employees, the Pay Statements Register, and the National Education Database. The individual level data provide us with information on man-hours, wages (constructed as annual earnings divided by contracted annual working hours), the worker's place of residence, length and type of education, and potential experience - calculated as a person's age minus the length of his education minus the age at which he/she started at compulsory primary school. This information makes it possible to link firm-level and individual-level information and to integrate individual-level data into a common data base and then aggregate to the firm level. ${ }^{1}$

\footnotetext{
${ }^{1}$ For a more detailed description of data sources used, see the Data Appendix of Nilsen et al.
} 


\section{Skill classification}

We start out by classifying workers into $K$ different skill categories, according to their relative efficiency. The categories are sorted in ascending order such that the least efficient workers are in category 1, and each category contains the same proportion, i.e., $100 / K$ percent, of total man-hours. If $M_{(k) t}$ denotes total man-hours in skill category $k$, for $k=1, \ldots, K$, then total man-hours, $M_{t}$, can be written as

$$
M_{t}=\sum_{k=1}^{K} M_{(k) t}
$$

A particular set of efficiency weights, $\lambda_{k}, k=1, \ldots, K$, with $\lambda_{k-1}<\lambda_{k}$, is applied to the man-hours in each category $k$, to calculate efficiency-adjusted aggregate man-hours, $\widetilde{M_{t}}$ :

$$
\widetilde{M}_{t}=\sum_{k=1}^{K} \lambda_{k} M_{(k) t}, \quad 1=\lambda_{1}<\lambda_{2}<\ldots<\lambda_{K},
$$

These parameters are calibrated based on the assumption of perfect substitution between workers, such that relative efficiency between a worker in skill category $k$ and 1 , $\lambda_{k}$, is equal to their relative wage. Instead of using the actual relative wages between individuals observed in the data to calculate $\lambda_{k}$, we use the skill-related part of the predicted wages, as motivated by the discussion in Section 1.

The following wage equation is estimated separately for each industry (for ease of exposition we suppress the index for industry throughout the paper):

$$
\ln \left(W_{p r t}\right)=Z_{r t} \gamma_{z}+X_{p t} \gamma_{x}+\nu_{p}+\varepsilon_{p r t}
$$

where $W_{p r t}$ is the hourly wage of person $p$ working in labor market region $r$ in year $t$. On the right hand side, we specify two (row) vectors with observed variables, $Z_{r t}$ and $X_{p t}$. The vector of explanatory variables $Z_{r t}$ consists of observed variables that are related to the labor market region $(r)$ where the individual works and the calendar year $(t)$, and is assumed to be unrelated to the individual's skill: ${ }^{2}$

$$
Z_{r t}=\text { (labor market region dummies, year-specific dummies). }
$$

(2009).

${ }^{2}$ The definition of the seven labor market region dummies is based on characteristics such as size and centrality (see http://www.ssb.no/english/subjects/06/sos110_en/sos.110_en.pdf). 
The other vector, $X_{p t}$, contains values of variables related to individual $p$ 's skill in year $t:^{3}$

$$
\begin{aligned}
X_{p t}= & \text { (years of schooling, powers of years of experience up to } 4 \text { 'th order, } \\
& \text { gender, type of education-dummies). }
\end{aligned}
$$

The attached coefficient vectors are denoted $\gamma_{z}$ and $\gamma_{x}$, respectively. The scalar $\nu_{p}$ is an unobserved individual random effect of individual $p$. Finally, $\varepsilon_{p r t}$ denotes a genuine error term.

Next we decompose the log wage, $\ln \left(W_{p r t}\right)$, into three parts:

$$
\ln \left(W_{p r t}\right)=\omega_{p t}+Z_{r t} \gamma_{2}+\varepsilon_{p r t}
$$

where

$$
\omega_{p t} \equiv X_{p t} \gamma_{1}+\nu_{p}
$$

is the only part which is relevant to skill measurement, while the second part; related to the variables in the vector $Z_{r t}$, and the third part; the transient noise $\varepsilon_{p r t}$, do not concern skill measurement.

To calculate the weights $\lambda_{k}$, and to classify workers into skill categories, only the skill-related part, $\omega_{p t}$, of the wage will be used, cf. (3). The detailed calculations are as follows: Consider all the values of $\omega_{p t}$ occurring in our sample and sort them in ascending order. To be specific, assume that $K=10$ (deciles), which is what we actually use in our application. Then let $\omega_{(1)}<\omega_{(2)}<\cdots<\omega_{(10)}$ denote the 5, 15, 25, ..., 95 percent quantiles in the empirical distribution of $\omega_{p t}$. The man-hours of person $p$ at time $t$ are allocated to category $k$ iff

$$
k=\underset{j}{\arg \min }\left|\omega_{p t}-\omega_{(j)}\right| .
$$

Thus $\omega_{(k)}$ is the median predicted wage (after removing the effect of noise, $\varepsilon_{p r t}$, and labor market region and time dummies, $Z_{r t}$ ) within category $k$. Finally, we calibrate the efficiency parameters using the relative median skill-related predicted wages:

$$
\lambda_{k}=\frac{\exp \left(\omega_{(k)}\right)}{\exp \left(\omega_{(1)}\right)}, k=1, \ldots, 10 .
$$

\footnotetext{
${ }^{3}$ The data investigation shows that mainly workers with the following three types of education are represented in the chosen industries: education in "General programs", "Business and Administration" and education in "Natural Sciences, Vocational and Technical subjects".
} 
The median $\omega_{(k)}$ is then the middle point within the $k$ 'th decile, and is chosen as the reference point as it is not vulnerable to outliers, in contrast to the corresponding mean value of $\omega_{p t}$. In general, the difference between $\omega_{(k)}$ and the mean value of $\omega_{p t}$ within the $k$ 'th decile is small, except for the highest decile, where the mean is influenced by a few high outliers. Of course, this framework can be used for any $K$, and the modified definitions of the $\omega_{(k)}$ follow straightforwardly.

In practice, $\omega_{(k)}$ and $\lambda_{k}$ must be estimated. This is done by replacing $\omega_{p t}$ with

$$
\widehat{\omega}_{p t} \equiv X_{p t} \widehat{\gamma}_{1}+\widehat{\nu}_{p}
$$

where $\widehat{\gamma}_{1}$ denotes the estimated parameter vector and $\widehat{\nu}_{p}$ is the predicted random effect of individual $p$ based on feasible GLS estimation. In our empirical analysis, the parameters $\omega_{(k)}$ and $\lambda_{k}$ are replaced by estimates, $\widehat{\omega}_{(k)}$ and $\widehat{\lambda}_{k}$, using $\widehat{\omega}_{p t}$ instead of $\omega_{p t}$. The unknown parameters in (2) are estimated by GLS using unbalanced panel data for each industry. The assumption that $v_{p}$ is a random effect is convenient in order to identify $\gamma_{x}$ - in particular the coefficient attached to years of schooling, which in our sample is close to being an individual-specific time-invariant variable.

An objection frequently raised against random effects models is that the GLSestimators applied to estimate them are biased if the latent effect is correlated with the observed right-hand side variables. However, in our setting there are several problems attached to using fixed effects estimators. First, for a substantial part of the individuals there are too few observations in order to obtain precise estimates. Second, most of the observed right-hand side variables are time-invariant or nearly so, which implies a genuine identification problem. Third, since we apply the wage equations also to predict wages for observations not included when estimating the wage equation (see below) the random effects specification seems more appropriate. In light of these three features we have chosen to stick to the random effects specification instead of the fixed effects specification.

Before we estimate the wage equation (2), we carry out some data cleaning. First, since wages of part time workers are particularly hampered by measurement errors, we omit data for part-time workers. Second, we omit wage observations which are viewed as being either unusually high or unusually low. The corresponding cut-off values are obtained using quantile regressions. For each industry, we perform quantile regressions 
for the 5 and 95 percent quantiles, respectively, to estimate these quantiles conditional on labor market region and calendar year (which are the only included regressors). When estimating the wage equations, we omit observations that are characterized by either hourly wages below the conditional 5 percent or above the conditional 95 percent quantiles. This procedure ensures smoother quantiles across time and labor market region compared to the raw data quantiles.

[Table 1: Wage equation estimation results]

The data cleaning referred to above has been done only when estimating the wage equation. The omitted observations are included again when performing the final TFP calculations. Based on the wage equations we predict the skill-related wages for all persons in every period they are observed. For workers not included in the estimation sample, we obtain $\widehat{\omega}_{p t}$ by using the observed $X_{p t}$ and setting $\widehat{\nu}_{p}=0$, which is the optimal ex ante estimate of the random effect.

The results from the wage equation estimations are reported in Table 1 . We see that the marginal returns to education are approximately 5 percent, in line with other studies based on Norwegian data (see for instance Hægeland et al., 1999). The coefficients attached to years of experience are hard to interpret directly, since the effect of experience is represented by a fourth order polynomial. If we only look at the first order term, we find returns of the same magnitude as for education. However, the marginal returns to experience is decreasing and becomes zero at around 30-32 years of experience, and negative thereafter. The effects of the other explanatory variables, such as gender, labor market region and type-of-education are all in line with our prior expectations.

[Figure 1: The efficiency parameters in different industries]

The calculated values of $\lambda_{k}$ for all the manufacturing industries are displayed in Figure 1. We see that there is considerable variation in $\lambda_{k}$ across the different industries, for a given decile $k$. In particular, $\lambda_{10}$ is highest in the typical high-tech industry Electrical equipment (which also have the highest share of workers with at least 13 years of education; about 35 percent), especially compared to the traditional lowtech industry Wood products (where the share of workers with at least 13 years of 
education is about 8 percent). One also notes that the curves of Electrical equipment and Chemical products are steeper at the upper part of the distribution, as shown by $\lambda_{10} / \lambda_{9}$ and $\lambda_{9} / \lambda_{8}$, compared to industries characterized by a large share of lowskilled workers. Thus the high-tech industries seem to employ and reward workers with especially high productivity.

We will consider different types of benchmark methods for calculating efficiency weighted total man-hours, $\widetilde{M}_{t}$. A trivial benchmark is, of course, to set $\widetilde{M}_{t}=M_{t}$, i.e., no skill adjustments. In the (more elaborate) benchmark method we will classify workers (or man-hours by a particular worker in a given year) into cells based on values of a sub-set of the covariates, $X_{p t}$, described above. Then we follow Zoghi (2008) and skill-adjust the change in input of labor services by calculating the change in a Törnqvist index. The weight of the workers in cell $j, j \in J$, is the skill-related wage bill for this group of workers divided by the total skill-related wage bills for all the groups. In our application we will consider a case with 12 cells. The classification is based on three variables: Education length, Experience and Gender, where Education length has two discrete outcomes: less than 13 years and at least 13 years, and Experience has three disjunct outcomes: Experience $\leq 7$ years; $8 \leq$ Experience $\leq 15$ years; Experience $\geq 16$ years. A listing of the cells with definitions is given in Table A.2 in the Appendix.

\section{Productivity growth analysis}

To analyse the importance of the choice of different skill measures, we consider a growth accounting framework at the industry level implicitly assuming constant returns to scale. Instead of sticking to a Cobb-Douglas production function specification with constant share-parameters, we allow for time-varying share-parameters and employ Törnqvist indices. As pointed out by Morrison Paul (1999, p. 43) and Diewert (1976) this choice is consistent with assuming a translog production function. The growth in labor productivity, $\Delta \ln \left(Y_{t} / M_{t}\right)$, where $Y_{t}$ and $M_{t}$ are valued added and the total number of man-hours at the industry level, respectively, is decomposed into contributions from heterogeneous labor (to be specified below), capital services, $K_{t}$, and 
a residual term, $\triangle T F P_{t}$. The latter denotes growth in total factor productivity. ${ }^{4}$ The expression for the relative growth in labor productivity is given by

$$
\Delta \ln \left(\frac{Y_{t}}{M_{t}}\right)=\alpha_{t} \Delta \ln \left(\frac{\widetilde{M_{t}}}{M_{t}}\right)+\left(1-\alpha_{t}\right) \Delta \ln \left(\frac{K_{t}}{M_{t}}\right)+\Delta T F P_{t}
$$

where $\widetilde{M}_{t}$ is aggregate skill-adjusted man-hours according to our proposed method, as defined in (1) or calculated according to the benchmark method. Equivalently, we can write

$$
\Delta T F P_{t}=\Delta \ln \left(\frac{Y_{t}}{\widetilde{M}_{t}}\right)-\left(1-\alpha_{t}\right) \Delta \ln \left(\frac{K_{t}}{\widetilde{M}_{t}}\right) .
$$

Using the benchmark method, we follow Zoghi (2008), and define

$$
\Delta \ln \left(\widetilde{M}_{t}\right)=\sum_{j \in J} 0.5\left(s_{j t}+s_{j, t-1}\right) \Delta \ln \left(M_{j t}\right)
$$

where $M_{j t}$ is the number of man-hours in cell $j$ at time $t$, and the $s_{j t}$ are weights defined as follows:

$$
s_{j t}=\frac{\exp \left(\widehat{\omega}_{j t}\right) M_{j t}}{\sum_{j \in J} \exp \left(\widehat{\omega}_{j t}\right) M_{j t}},
$$

where $\widehat{\omega}_{j t}$ denotes the mean value of $\widehat{\omega}_{p t}$ belonging to cell $j$ in year $t$, cf. (3). Following the traditional approach in growth accounting, the industry level share-parameter $\alpha_{t}$ is calibrated using the arithmetic mean of the cost share of labor (i.e., the total wage bill divided by total factor costs) in period $t$ and $t-1 .^{5}$

For each industry in the manufacturing sector, we compare the TFP growth obtained from (5) with two other cases: First, when $\lambda_{k} \equiv 1$ for all $k$ and hence $\widetilde{M}_{t}$ in $(5)$ is replaced by the non-adjusted man-hours, $M_{t}$, and second, when $\Delta \ln \left(\widetilde{M}_{t}\right)$ is calculated as in (6) based on an index set, $J$, consisting of 12 categories. Note that the left-hand side of (5) does not depend on the skill measure used, since $M_{t}$ equals total man-hours.

[Table 2: Growth equation estimates]

We see from the results reported in Table 2 that labor costs as a share of total factor costs are approximately 70 percent on average, but vary considerably, from about 80

\footnotetext{
${ }^{4}$ In the TFP growth calculations we only include firms with at least three years of contiguous data and no missing variables.

${ }^{5}$ In the current paper we do not consider the link between TFP growth at the plant/firm and the industry levels, as discussed in Hulten (2001, pp. 38-39). Cf. also Baily et al. (1992) and Foster et al. (2001).
} 
percent in Electrical equipment and Transport and communication to about 50 percent in Mineral products. Furthermore, labor productivity growth (3.5 percent annually, averaging over all the industries) is mainly explained by capital deepening. Growth in labor quality also contributes: Regardless of which method is used to skill-adjust labor input, the growth in skill-adjusted man-hours is higher than the growth in number of man-hours (i.e., $\Delta \ln \left(\widetilde{M}_{t} / M_{t}\right)$ is positive in all industries). The lower value of TFPgrowth using our method compared to the benchmark method is solely accounted for by a higher growth in skill-adjusted man-hours obtained with our method.

In Table 2 we also report the mean annual growth in labor productivity over the period 1995-2005 together with the mean annual TFP growth according to (i) the case without any skill adjustment, (ii) the benchmark method, and (iii) the new wage equation based skill-adjusted measure of labor input put forward in this paper.

With no skill adjustment, the mean annual TFP growth varies between 0.5 and 3.7 percent, with 2.5 as an average across the industries. In all the industries the mean annual TFP growth varies between 0.5 and 3.7 percent, with 2.5 as an average across the industries. In all the industries the mean annual TFP growth is lower using the benchmark method compared to the method without skill adjustment. Our proposed efficency adjustment leads to an even wider difference. The latter difference varies from less than 0.1 percentage point to 0.4 percentage points. On average, our method leads to 0.5 percentage points lower TFP growth than the case with no quality adjustment, and 0.3 percentage points lower growth compared to the benchmark method. Thus, our method unambigously leads to reduced TFP growth, by allowing more of the change in value-added to be picked up by the measurable components compared to the benchmark method.

We have considered some robustness checks. First, we have added type of education as an extra dimension for the benchmark method. This variable has three outcomes: General programs; Vocational and technical subjects; and Other type of education. Thus, the benchmark method now involves 48 cells. We find for all industries that the TFP growth for this extended version of the benchmark method is practically indistinguishable to the one obtained for the benchmark method using 12 cells. This resembles the conclusion obtained by Fosgerau et al. (2002) using Danish data. As a 
second robustness issue we have investigated how sensitive the results are with respect to the cut-off values used when trimming the data set for the full time workers. Instead of applying the thresholds corresponding to the 5 and 95 percent conditional quantiles, we have employed the 1 and 99 percent thresholds. It turns out that even though the estimates of the parameters in the wage equations are somewhat changed, the predicted values obtained from the estimated wage equations are very similar. Accordingly, the estimated TFP growth is not significantly influenced by the application of these alternative cut-off values.

Why does our method for skill adjustment yield a higher increase in labor quality growth than what is obtained using the benchmark method? We have seen that this has nothing to do with the number of cells used in connection with the benchmark method. The main difference between the two approaches lies in our method's ordering of the skill categories according to relative efficiency. In contrast the benchmark method leads to categories (cells) that cannot be ordered. A consequence of this is that movements up and down the deciles over time (for a given employee) are more common than movements between cells using the benchmark method. This pattern is clearly visible from the transition matrices of Tables A.3 and A.4 in the Appendix, which show transition rates between the different categories using the two methods. These transion rates are empirical transition probabilities (relative frequencies) and illustrate to what extent persons move from one skill category to another between two subsequent years during the observation period. The additional variability in $\widetilde{M}_{t} / M_{t}$ using our method instead of the benchmark method enables us to better explain labor productivity growth, as is seen from the decrease in the (residual) TFP-growth term when switching from the benchmark method to our quantile-based method.

A final important question is whether the differences in the mean TFP growth using the various skill measures are statistically significant. To answer this question we provide standard errors of the mean difference in TFP growth by means of bootstrapping. The bootstrap works as follows. From the dataset used to produce the TFP growth estimates reported in Table 2 we draw a sample of $N$ firms (with replacement). For each of these $N$ firms we use the entire time series of output, wage costs, hours of work, and capital. In each replication we calculate the difference between the mean 
TFP growth obtained using our quantile-based method and the benchmark method. After 250 bootstrap replications, we calculate the standard deviation of the differences in mean TFP growth over the bootstrap sample and take this as an estimate of the standard error of the difference in mean TFP growth. We find that the difference in estimated TFP growth between the quantile-based method and the benchmark method is statistically significant (the estimated standard error of the difference equals 0.09 percentage points). If we now consider a 50-years horizon as an example, which is not uncommon in long-run projections, a constant annual TFP growth rate of 2.0 instead of 2.3 percent implies a 42 percentage point lower TFP growth over such a time span. Thus, an improved measure of labor input has non-negligible effects when considering growth accounting in the long term.

\section{Concluding remarks}

In this paper we have suggested a new method for constructing an index of labor services. Extracting and classifying skill-related predicted wages plays a decisive role in our quantile (decile)-based method. We calculate the growth of TFP for 11 manufacturing industries using this new measure of labor services and compare the results with what is obtained using (i) a more traditional method for accounting for labor heterogeneity within a growth accounting framework and (ii) assuming homogeneous labor. We find that the new method gives a lower growth in TFP than both (i) and (ii). For the manufacturing sector as a whole we find that the mean annual growth in TFP is 0.3 percentage points lower using the new measure of labor services instead of the more traditional measure (i) based on a set of predefined cells, which we have exemplified by dividing the observations into 12 cells according to length of education, working experience and gender. This can be interpreted as the measure put forward in this paper captures more of the growth in labor quality than the more traditional measure.

While our main concern in the present paper has been to assess the importance of skill adjustment for calculating growth in TFP, elaborations of our approach should be of interest, given the importance of the issue discussed. Perhaps the most natural one is to extend the information set used in the estimation of the wage equations with 
firm-specific variables, e.g. represented by dummy variables of firms such as in Abowd et al. (1999). Another relevant topic is to relax the constant returns to scale restriction when decomposing the growth in labor productivity. 


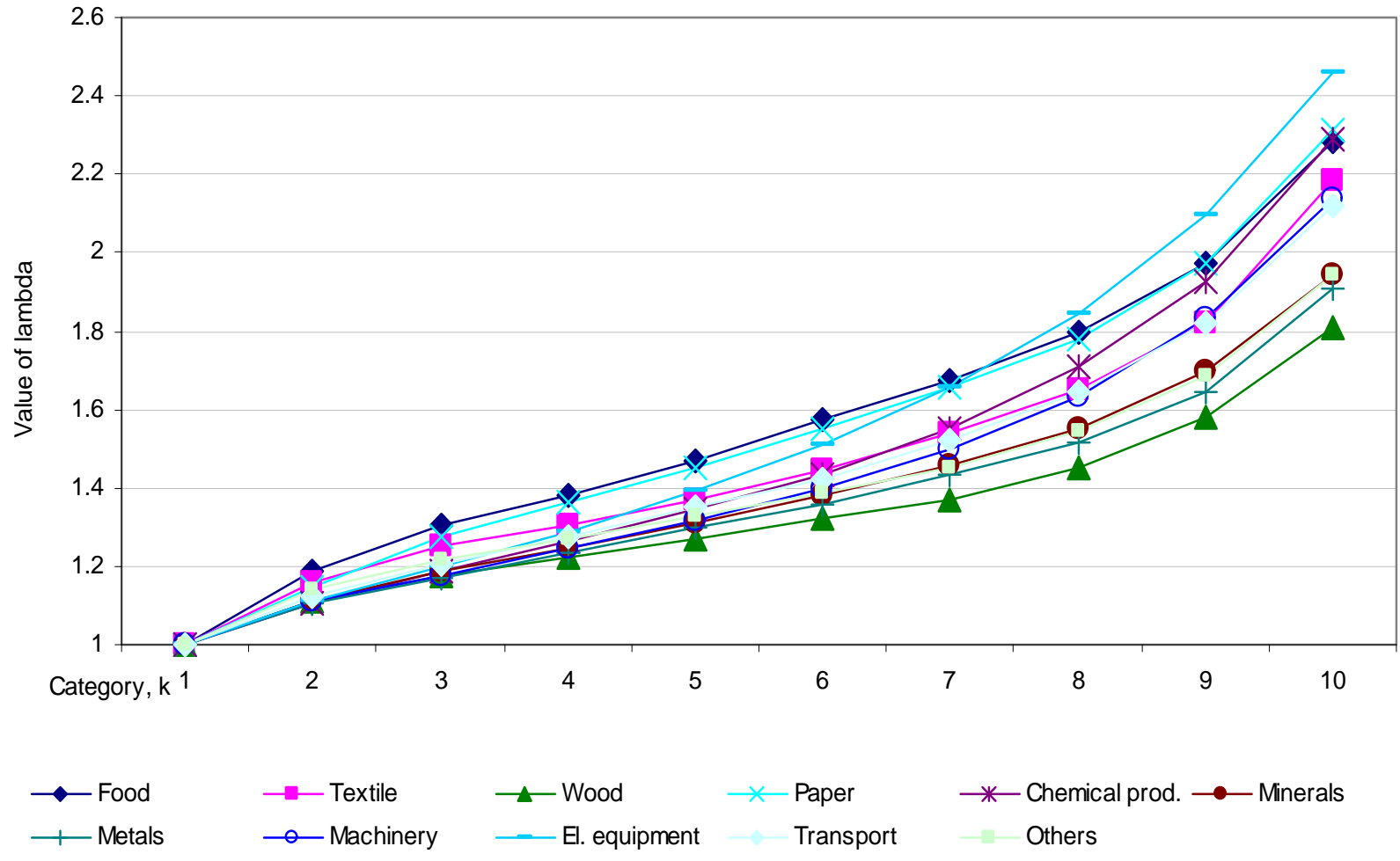

Figure 1: Estimated efficiency parameters, $\lambda_{k}$, for different industries 


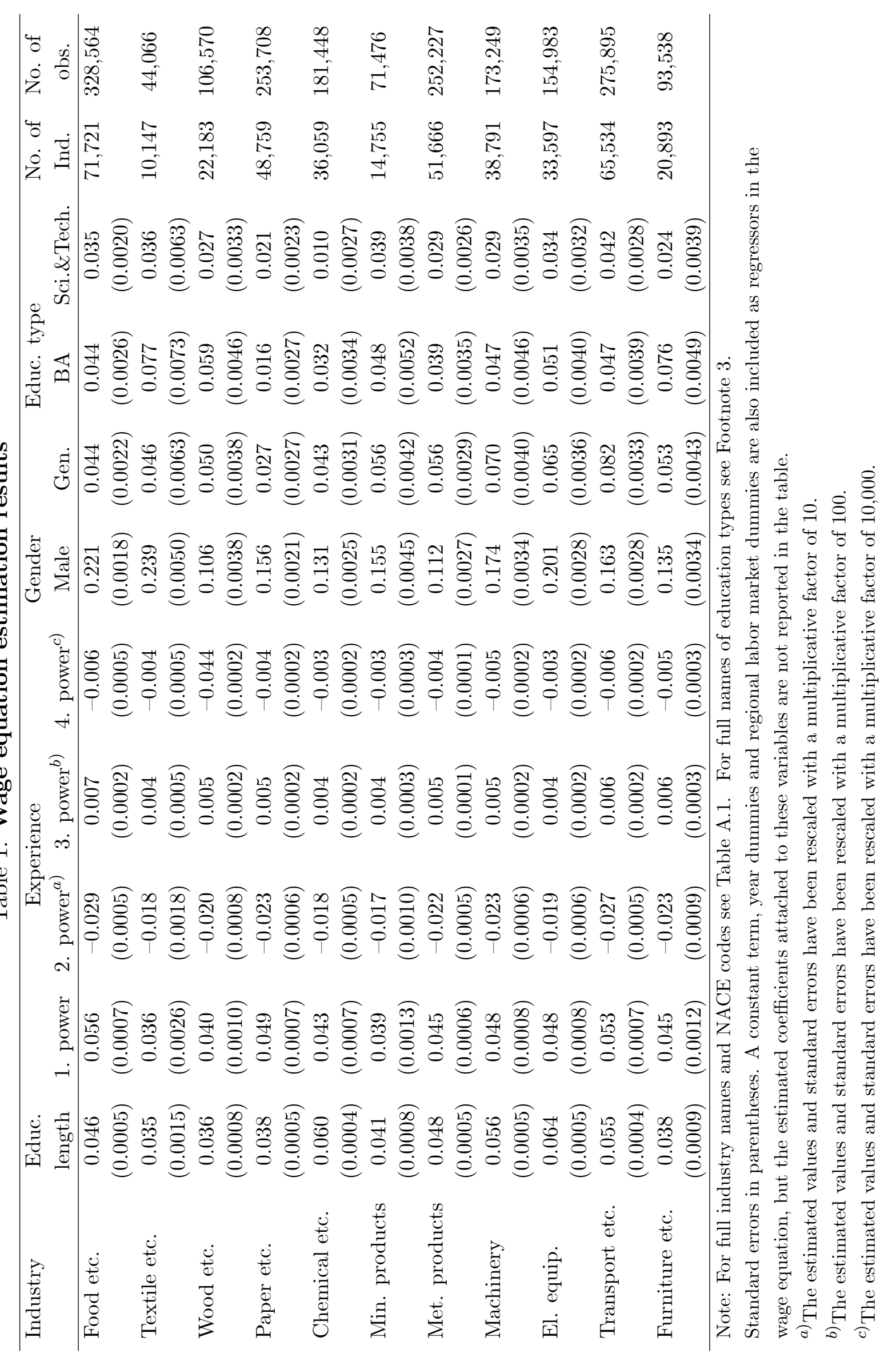




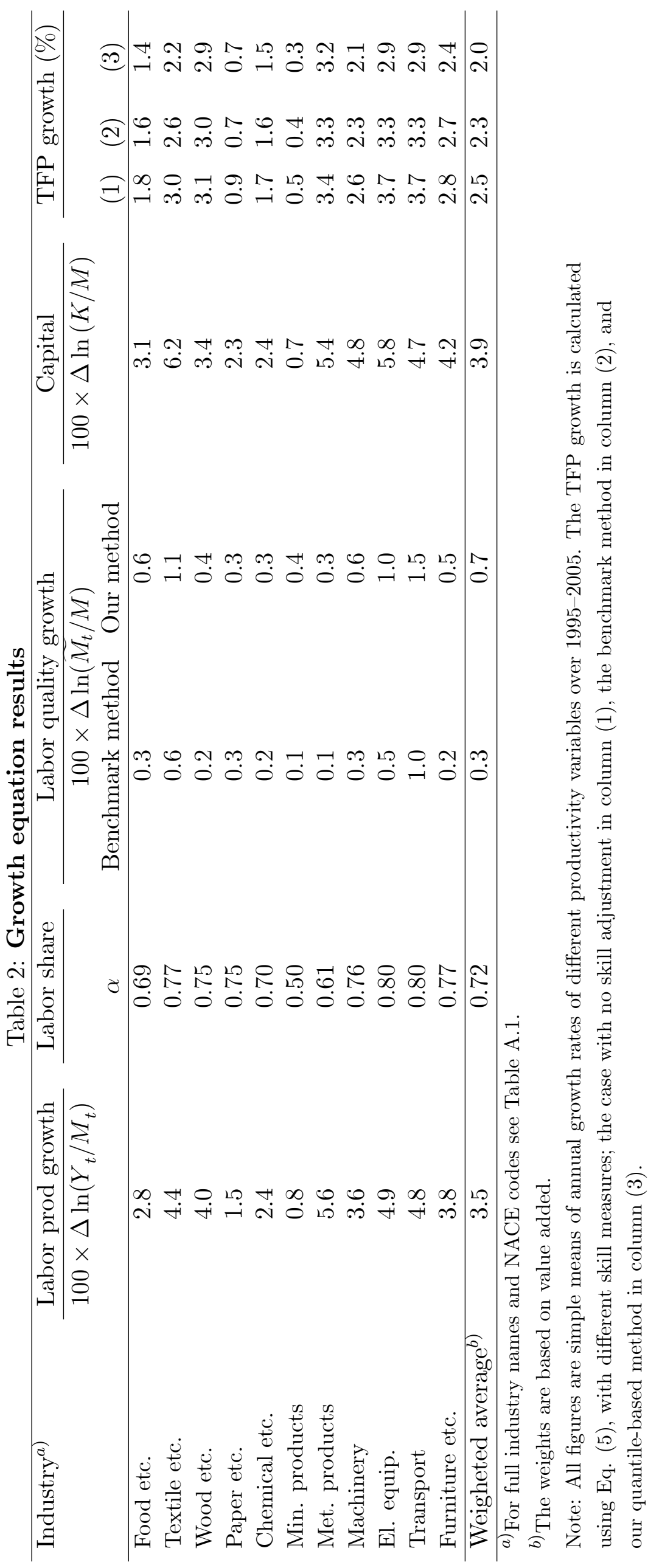




\section{References}

[1] Abowd, J.M., F. Kramarz and D.N. Margolis, "High Wage Workers and High Wage Firms," Econometrica, 67, 251-333, 1999.

[2] Ahmad, N., F. Lequiller, P. Marianna, D. Pilat, P. Schreyer and A. Wölfl, "Comparing Labour Productivity in the OECD Area: The Role of Measurement," OECD Statistics Working Papers 2003/5, OECD, Paris, 2003.

[3] Baily, M.N., C. Hulten and D. Campbell, "Productivity Dynamics in Manufacturing Plants," Brookings Papers on Economic Activity, Microeconomics, 187-267, 1992 (with discussion).

[4] Bolli, T. and M. Zurlinden, "Measurement of Labor Quality Growth caused by Unobservable Characteristics," Swiss National Bank Working Papers 2009-1, 2009.

[5] Boulhol, H. and L. Turner, "Employment - Productivity Trade-Off and Labour Composition," Working Paper No. 698, Economics Department, OECD, 2009.

[6] Bureau of Labor Statistics, "Labor Composition and U.S. Productivity Growth, 1948-90," Bulletin 2426, U.S. Department of Labor, Bureau of Labor Statistics, December, 1993.

[7] Diewert, W.E., "Exact and Superlative Index Numbers," Journal of Econometrics, 4, 115-145, 1976.

[8] Fosgerau, M., S.E. Hougaard Jensen and A. Sørensen, "Measuring Educational Heterogeneity and Labor Quality: A Note," Review of Income and Wealth, 48, 261-269, 2002.

[9] Foster, L., Haltiwanger, J. and C.J. Krizan, "Aggregate Productivity Growth: Lessons from Microeconomic Evidence," in: C.R. Hulten, E.R. Dean and M.J. Harper (eds.), New Developments in Productivity Analysis, Chicago University Press, Chicago, 303-363, 2001.

[10] Griliches, Z., "Measuring Inputs in Agriculture: A Critical Survey," Journal of Farm Economics, 42, 1411-1433, 1960. 
[11] Hulten, C., "Total Factor Productivity: A Short Biography," in C.R. Hulten, E.R. Dean and M.J. Harper (eds.), New Developments in Productivity Analysis, Chicago University Press, Chicago, 1-47, 2001.

[12] Hægeland, T., T.J. Klette and K.G. Salvanes, "Declining Returns to Education in Norway? Comparing Estimates across Cohorts, Sectors and Over Time," Scandinavian Journal of Economics, 101, 555-576, 1999.

[13] Jorgenson, D.W., F.M. Gollop and B.M. Fraumeni, Productivity and U.S. Economic Growth, Harvard University Press, Cambridge, MA, 1987.

[14] Lacuesta, A., Puente, S. and P. Cuadrado, "Omitted Variables in the Measure of a Labour Quality Index: The case of Spain", Bank of Spain Working Paper 08/35. (Forthcoming in Review of Income and Wealth), 2008.

[15] Morrison Paul, C.J., Cost Structure and the Measurement of Economic Performance: Productivity, Utilization, Cost Economics and Related Performance Indicators, Kluwer Academic Publishers, London, 1999.

[16] Nilsen, Ø.A., A. Raknerud, M. Rybalka and T. Skjerpen, "Lumpy Investments, Factor Adjustments, and Labour Productivity," Oxford Economic Papers, 61, 104$127,2009$.

[17] OECD, Measuring Productivity OECD Manual: Measurement of Aggregate and Industry-Level Productivity Growth, OECD, Paris, 2001.

[18] Raknerud, A., D. Rønningen and T. Skjerpen, "A Method for Improved Capital Measurement by Combining Accounts and Firm Investment Data," Review of Income and Wealth, 53, 397-421, 2007.

[19] Schwerdt, G. and J. Turunen, "Growth in Euro Area Labor Quality," Review of Income and Wealth, 53, 716-734, 2007.

[20] Zoghi, C., "Measuring Labor Composition: A Comparison of Alternate Methodologies," Mimeo, US Bureau of Labor Statistics, 2008. 


\section{Appendix: Supplementary tables}

Table A.1: Industries and NACE codes

\begin{tabular}{lll}
\hline Industry & NACE codes & Abbreviated industry label \\
\hline Food, beverages and tobacco & $15-16$ & Food etc. \\
Textile and leather products & $17-19$ & Textile etc. \\
Wood and wood products & 20 & Wood etc. \\
Paper and publishing & 22 & Paper etc. \\
Chemical and plastic products & 25 & Chemical etc. \\
Mineral products & 26 & Min. products \\
Metal products & $27-28$ & Met. products \\
Machinery & 29 & Machinery \\
Electrical equipment & $30-33$ & El. equip. \\
Transport and communication & $34-35$ & Transport etc. \\
Furniture and others & $36-37$ & Furniture etc. \\
\hline
\end{tabular}


Table A.2: Listing of cells for the benchmark method

\begin{tabular}{lcll}
\hline Cell & Length of education & Experience & Gender \\
\hline I & $<13$ years & Experience $<7$ years & Male \\
II & $<13$ years & Experience $<7$ years & Female \\
III & $<13$ years & 8 years $\leq$ Experience $<15$ years & Male \\
IV & $<13$ years & 8 years $\leq$ Experience $<15$ years & Female \\
V & $<13$ years & Experience $\geq 16$ years & Male \\
VI & $<13$ years & Experience $\geq 16$ years & Female \\
VII & $\geq 13$ years & Experience $<7$ years & Male \\
VIII & $\geq 13$ years & Experience $<7$ years & Female \\
IX & $\geq 13$ years & 8 years $\leq$ Experience $<15$ years & Male \\
X & $\geq 13$ years & 8 years $\leq$ Experience $<15$ years & Female \\
XI & $\geq 13$ years & Experience $\geq 16$ years & Male \\
XII & $\geq 13$ years & Experience $\geq 16$ years & Female \\
\hline
\end{tabular}


Table A.3: Transition rates between different labor quality deciles

\begin{tabular}{lcccccccccc}
\hline & & & \multicolumn{1}{c}{ Deciles } \\
Deciles & 1 & 2 & 3 & 4 & 5 & 6 & 7 & 8 & 9 & 10 \\
\hline 1 & 0.84 & 0.16 & & & & & & & & \\
2 & 0.01 & 0.81 & 0.18 & & & & & & & \\
3 & & 0.02 & 0.79 & 0.19 & & & & & & \\
4 & & & 0.03 & 0.80 & 0.17 & & & & & \\
5 & & & & 0.02 & 0.81 & 0.17 & & & & \\
6 & & & & & 0.02 & 0.84 & 0.14 & & & \\
7 & & & & & & 0.02 & 0.87 & 0.11 & & \\
8 & & & & & & & 0.01 & 0.91 & 0.08 & \\
9 & & & & & & & & 0.01 & 0.95 & 0.05 \\
10 & & & & & & & & & 0.01 & 0.99 \\
\hline
\end{tabular}


Table A.4: Transition rates between cells for the benchmark method*

\begin{tabular}{|c|c|c|c|c|c|c|c|c|c|c|c|c|}
\hline & Cells & & & & & & & & & & & \\
\hline Cells & I & II & III & IV & $\mathrm{V}$ & VI & VII & VIII & IX & $\mathrm{X}$ & XI & XII \\
\hline I & 0.84 & & 0.14 & & & & 0.02 & & & & & \\
\hline II & & 0.84 & & 0.12 & & & & 0.04 & & & & \\
\hline III & & & 0.86 & & 0.14 & & & & & & & \\
\hline IV & & & & 0.85 & & 0.15 & & & & & & \\
\hline $\mathrm{V}$ & & & & & 1.00 & & & & & & & \\
\hline VI & & & & & & 1.00 & & & & & & \\
\hline VII & & & & & & & 0.85 & & 0.15 & & & \\
\hline VIII & & & & & & & & 0.86 & & 0.14 & & \\
\hline IX & & & & & & & & & 0.88 & & 0.12 & \\
\hline$X$ & & & & & & & & & & 0.89 & & 0.11 \\
\hline XI & & & & & & & & & & & 1.00 & \\
\hline XII & & & & & & & & & & & & 1.00 \\
\hline
\end{tabular}

${ }^{*}$ See Table A.2 for definitions of the cells. 